\title{
Divergence and Curl of COVID19 Spreading in the Lower Peninsula of Michigan
}

\author{
Yanshuo Wang ${ }^{1}$ \\ ${ }^{1}$ Reliability and Data Mining Consultant, LLLW Inc., Lansing, Michigan, USA \\ Correspondence: Yanshuo Wang, LLLW Inc., P.O. Box 25124, Lansing, MI 48190, USA.
}

Received: November 23, 2021

Accepted: December 23, $2021 \quad$ Online Published: December 29, 2021

doi:10.5539/cis.v15n1p32

URL: https://doi.org/10.5539/cis.v15n1p32

\begin{abstract}
This paper explores the COVID19 transmission pattern and circulation dynamics in the Euclidean space at the lower peninsula of Michigan by using the divergence and curl concept in vector field. The COVID19 transmission volume flux can be calculated for each county by using vector divergence. The results shows Wayne county had the highest divergence (162660), the Kent county had the second highest divergence (152540), and the Saginaw county had the third highest divergence (103240), the divergence is positive which means the COVID19 virus was transmitted from these counties to other places. The results also shows Monroe county had the lowest divergence (-187843), the Allegan county had the second lowest number in divergence (-90824), the divergence is negative which means the COVID19 virus was transmitted from other places to these counties. The circulation of the virus is also calculated by using vector curl. The positive curl means that the virus has circulated in a counter-clockwise direction, and the negative curl means the virus has circulated in a clockwise direction.

The divergence is an operator of the COVID19 transmission vector field, which produces a scalar field giving the quantity of the transmission vector field's source at each location. The COVID19 spreading volume density of the outward flux of transmission field is represented by divergence around a given location.

The curl is an operator of the COVID19 transmission field, which describes the circulation of a transmission vector field. The curl at a location in COVID19 transmission field is represented by a vector whose length and direction denote the magnitude and axis of the maximum circulation. The curl of a transmission field is formally defined as the circulation density at each location of COVID19 transmission field.
\end{abstract}

Keywords: COVID19, divergence, curl, transmission, circulation

\section{Introduction}

\subsection{Introduce the Problem}

It was announced by the World Health Organization (WHO) that COVID19 was first localized in Wuhan, Hubei Province, China in December, 2019, and it has been a significant human threat to the public health around the globe.

As of April 8, 2021 globally, there have been about 0.135 billion confirmed case, and about 2.9 million reported deaths (WorldOMeters, 2021). In the U.S.A., there are about 31.7 million confirmed cases, and about 0.57 million reported deaths (WorldOMeters, 2021). In the state of Michigan, there are about 804,031confirmed cases and about 17,450 reported death at the time author wrote this paper (Michigan Department of Health, 2021).

\subsection{Epidemiological Models}

The dynamics of the spreading and transmission of the COVID19 around the globe are still complicated to explain. Many researchers have developed mathematics models attempting to describe the dynamics of the characteristics of a novel disease reigns.

There are existing epidemiological models used in the pandemic prediction.

\subsubsection{Exponential Model}

It is believed that most epidemics grow approximately exponentially during the initial phase of an epidemic (Ranjan, R., 2020). I( $t$ ) is the number of "diagnosed infected" case, $t$ is the time which is measured in days. 


$$
\begin{gathered}
I(t)=I_{0} e^{r t} \\
\frac{d I(t)}{d t}=r I(t)=r I_{0} e^{r t}
\end{gathered}
$$

where $r$ is the growth rate, $I_{0}$ is the constant that can be calculated by fitting the data.

\subsubsection{Susceptible-Infectious-Recovered (SIR) Model}

SIR models are compartmental models used to simplify the mathematical modelling of infectious disease.

$$
\begin{array}{r}
\frac{d S(t)}{d t}=-\frac{\beta}{N} S(t) I(t) \\
\frac{d I(t)}{d t}=\beta S(t) I(t)-\gamma I(t) \\
\frac{d R(t)}{d t}=\gamma I(t)
\end{array}
$$

where $S(t)$ is the number of susceptible individuals, $I(t)$ is the number of infectious individuals, and $R(t)$ is the number of recovered individuals; $\beta$ is the transmission rate per infectious individual, and $\gamma$ is the recovery rate, $N$ is the population, $N=S(t)+I(t)+R(t)$ (Ma, J. 2020).

The basic reproduction number is given as:

$$
R_{0}=\frac{\beta}{\gamma}\left(1-\frac{I_{0}}{N}\right)
$$

The SIR models have been used to make the predictions for epidemic and COVID19 (Ranjan, R. 2020; Canabarro, etc. 2020; Liu, etc 2021; Ma, J. 2020).

\subsubsection{Logistic Model}

The logistic model was developed by Belgian mathematician Pierre Verhulst (1838). The logistic model is the model that shows initially exponential growth followed by a gradual slowing down and a saturation (Ma J. 2020; Bhardwaj, R. 2020)

$$
\begin{gathered}
\frac{d C(t)}{d t}=r C(t)\left(1-\frac{C(t)}{K}\right) \\
C(t)=\frac{K C_{0}}{C_{0}+\left(K-C_{0}\right) e^{-r t}}
\end{gathered}
$$

where $C(t)$ is the cumulative total numbers of infectious, $r$ is the exponential growth rate, $K$ is the upper limit of population growth and it is called carrying capacity. $C_{0}$ is the $C(t)$ when $t=0$.

\subsubsection{Piece Wise Crow-AMSAA Model}

The total confirmed infected cases or deaths $N(t)$ can be expressed when Crow-AMSAA model applies, which is denoted by:

$$
\begin{gathered}
N(t)=\lambda t^{\beta} \\
\operatorname{Ln} N(t)=\operatorname{Ln}(\lambda)+\beta \operatorname{Ln}(t)
\end{gathered}
$$

where $t$ is the time measured in days, $\lambda$ is the constant and $\beta$ is the slope of the transmission.

The piece wise Crow-AMSAA model was used to calculate the $\beta$ slope at different time period (Wang, Y., 2020).

\subsection{Our Research}

All the above epidemiology model is modeling the COVID19 spreading rate in terms of time $t$. In this paper, the vector divergence and curl concept is used to describe the COVID19 spreading density and circulation density in the Euclidean space ( $x$ and $y$ ).

The vector field divergence and curl operators have been used in an electrical magnetic field, fluid field (Wu, W.Y. 1989) and so on. The COVID19 transmission can be treated as a vector field that can use vector divergence and curl operators to calculate the spreading density and the circulation density. Divergence is the scalar, but curl is the vector. 
The vector divergence and curl methodologies are introduced in section 2. The data analysis of COVID19 divergence and curl of the lower peninsula of Michigan is described in section 3. The discussion is in section 4 . The conclusion and the prospect of future research is discussed in section 5.

\section{Method}

\subsection{Divergence}

In vector calculus, divergence is a vector operator which is a scalar field to describe the divergence of a vector at a given point. The divergence represents the volume density of the outward flux of a vector field from an infinitesimal volume around a given point.

The divergence of a vector field $T(x)$ at a point $x_{0}$ is defined as the limit of the ratio of the surface integral of $T$ out of the surface of a closed volume $V$ enclosing $x_{0}$ to the volume of $V$, as $V$ shrinks to zero

$$
\operatorname{div} \boldsymbol{T} \mid x_{0}=\lim _{V \rightarrow 0} \frac{1}{|V|} \oiint \mathrm{S}(\mathrm{V}) \boldsymbol{T} . \check{\mathrm{n}} d S
$$

where $|V|$ is the volume of $V, S(V)$ is the boundary of $V$, and is the outward unit normal to that surface. It can be shown that the above limit always converges to the same value for any sequence of volumes that contain $x_{0}$ and approach zero volume. The result, $\operatorname{div} \boldsymbol{T}$, is a scalar function of $x$.

In three-dimensional Cartesian coordinates, the divergence of a continuously differentiable vector field $\boldsymbol{T}=$ $T_{\mathrm{x}} \boldsymbol{i}+T_{\mathrm{y}} \boldsymbol{j}+T_{\mathrm{z}} \boldsymbol{k}$ is defined as the scalar-valued function:

$$
\operatorname{div} \boldsymbol{T}=\boldsymbol{\nabla} \cdot \boldsymbol{T}=\left(\frac{\partial}{\partial x}, \frac{\partial}{\partial y}, \frac{\partial}{\partial z}\right) \cdot\left(T_{\mathrm{x}}, T_{\mathrm{y}}, T_{\mathrm{z}}\right)=\frac{\partial T_{\mathrm{x}}}{\partial x}+\frac{\partial T_{\mathrm{y}}}{\partial y}+\frac{\partial T_{\mathrm{z}}}{\partial z}
$$
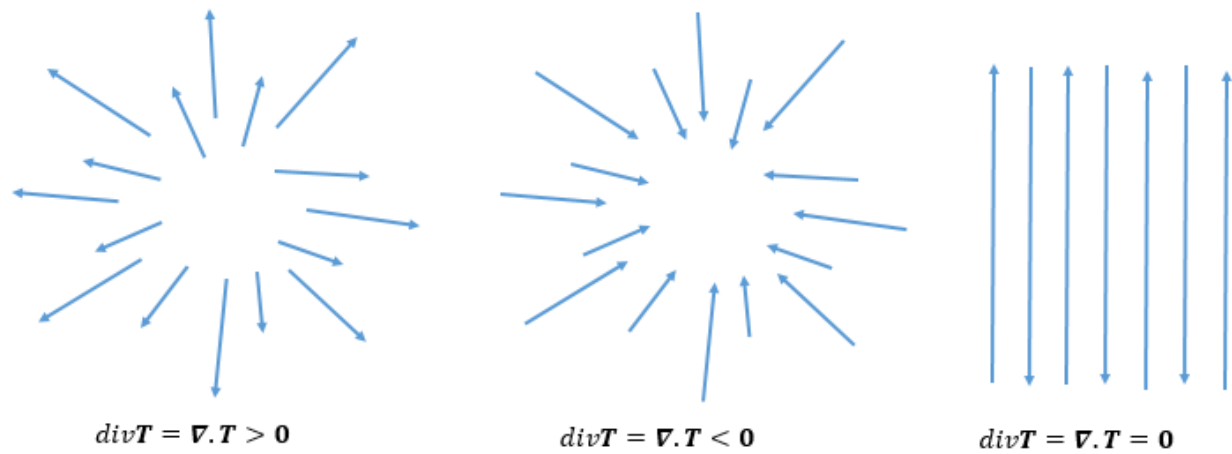

Figure 1. Description of divergence

Note. Divergence of vector $\boldsymbol{T}$ : when $\operatorname{div} \boldsymbol{T}>0$, the vector flux going to outward; when $\operatorname{div} \boldsymbol{T}<0$, the vector flux going to inward; when $\operatorname{div} \boldsymbol{T}=0$, that the amount going into a region equals the amount coming out.

\subsection{Curl}

In vector calculus, the curl is a vector operator that describes the infinitesimal circulation of a vector field in three-dimensional Euclidean space. The curl at a point in the field is represented by a vector whose length and direction denote the magnitude and axis of the maximum circulation. The curl of a field is formally defined as the circulation density at each point of the field.

The curl of vector $\boldsymbol{T}$ is denoted as $\operatorname{Cur} \boldsymbol{T}, \boldsymbol{R o t} \boldsymbol{T}$ or $\nabla \times \boldsymbol{T}$

Implicitly, curl is defined at a point $p$ as (Riley,K. F., Hobson, M.P., \& Bence, S.J., 2010; Spiegel, M.R., Lipschutz,S., \& Spellman, D., 2009) and denoted by:

$$
(\boldsymbol{\nabla} \times \boldsymbol{T})(p) . \check{\mathrm{n}} \stackrel{\text { def }}{=} \lim _{A \rightarrow 0} \frac{1}{|A|} \oint \mathrm{C} \boldsymbol{T} . d \boldsymbol{r}
$$

where the line integral is calculated along the boundary $C$ of the area $A$ in (13). $|A|$ being the magnitude of the area. This equation defines the projection of the curl of $\boldsymbol{T}$ onto. The infinitesimal surfaces bounded by $C$ have as their normal. $C$ is oriented via the right-hand rule. 


$$
(\boldsymbol{\nabla} \times \boldsymbol{T})=\left[\begin{array}{ccc}
\check{\mathrm{l}} & \check{\mathrm{\jmath}} & \check{\mathrm{k}} \\
\frac{\partial}{\partial x} & \frac{\partial}{\partial y} & \frac{\partial}{\partial z} \\
T_{\mathrm{x}} & T_{\mathrm{y}} & T_{\mathrm{z}}
\end{array}\right]
$$

where $i, j$, and $k$ are the unit vectors for the $x$-, $y$-, and $z$-axes, respectively. This expands as follows

$$
(\boldsymbol{\nabla} \times \boldsymbol{T})=\left(\frac{\partial T_{\mathrm{z}}}{\partial y}-\frac{\partial T_{\mathrm{y}}}{\partial z}\right) \check{\mathrm{l}}+\left(\frac{\partial T_{\mathrm{x}}}{\partial z}-\frac{\partial T_{\mathrm{z}}}{\partial x}\right) \check{\mathrm{\jmath}}+\left(\frac{\partial T_{\mathrm{y}}}{\partial x}-\frac{\partial T_{\mathrm{x}}}{\partial y}\right) \check{\mathrm{k}}=\left[\begin{array}{c}
\frac{\partial T_{\mathrm{z}}}{\partial y}-\frac{\partial T_{\mathrm{y}}}{\partial z} \\
\frac{\partial T_{\mathrm{x}}}{\partial z}-\frac{\partial T_{\mathrm{z}}}{\partial x} \\
\frac{\partial T_{\mathrm{y}}}{\partial x}-\frac{\partial T_{\mathrm{x}}}{\partial y}
\end{array}\right]
$$

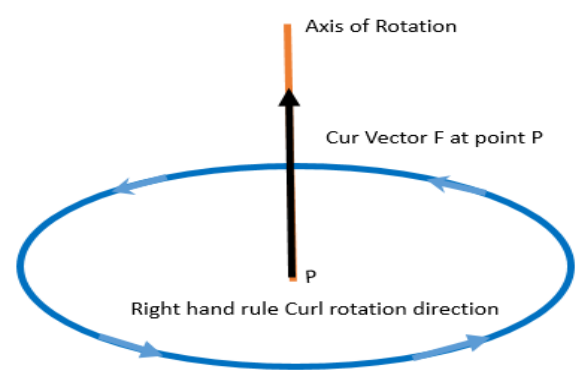

Figure 2. Rotation of Curl follows right hand rule

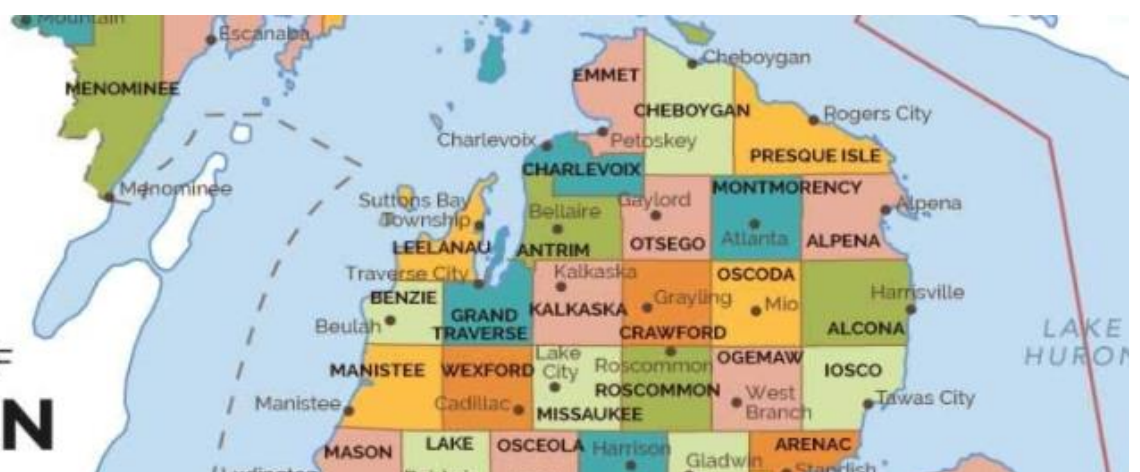

COUNTY MAP OF MICHIGAN
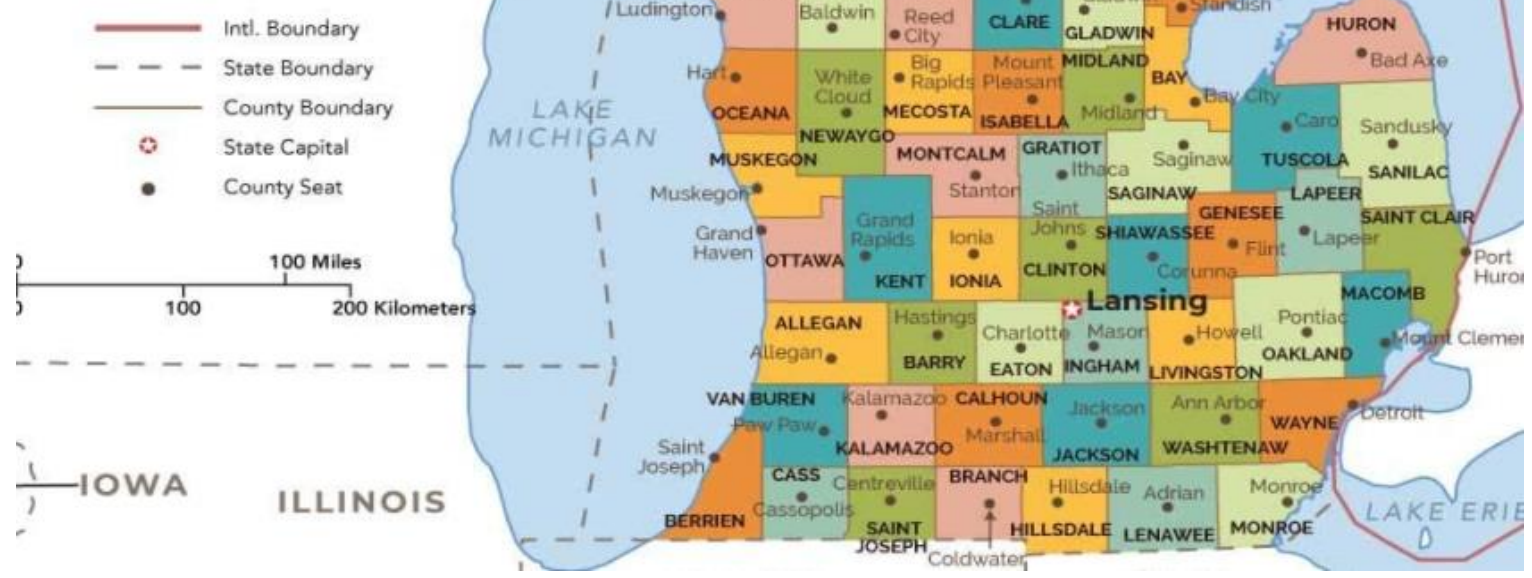

ILLINOIS

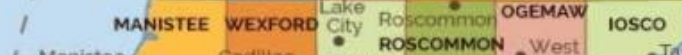

Figure 3. Map of Lower Pennisular Michigan

Note. The Map of Lower Peninsula of Michigan with Major cities and county capitals. (https://www.mapsofworld.com/usa/states/michigan/michigan-county-map.html) 


\section{Data Analysis}

The cumulative COVID 19 infected data of the lower peninsula of Michigan by April, 72021 was applied to calculate the divergence and curl of the disease transmission. There are 68 counties in the Lower Peninsula of Michigan. The data of COVID19 infected cases can be found at (Michigan Department of Health, 2021).

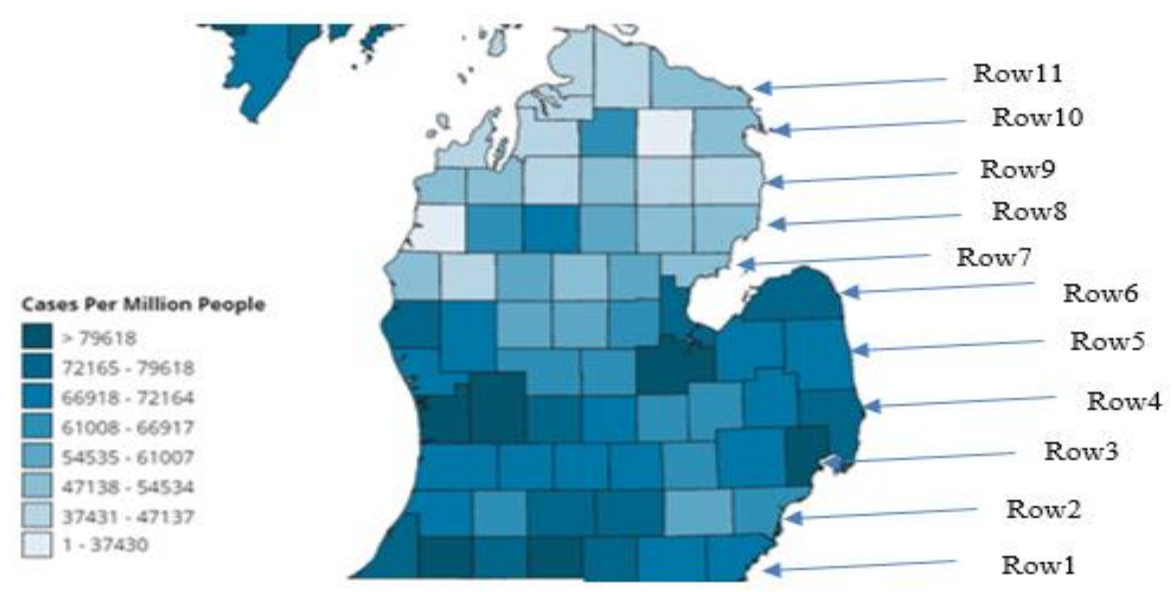

Figure 4. Infected Cases at the Lower Peninsula of Michigan on April 7, 2021

Note. This figure is from Michigan Department of Health, https://www.michigan.gov/coronavirus/0,9753,7-406-98163_98173---,00.html

Assumption:

1. The transmission vector $T$ at each county can be expressed by: $\boldsymbol{T}=T_{\mathrm{x}} \check{\mathrm{I}}+T_{\mathrm{y}} \breve{\mathrm{J}}$

$$
\begin{aligned}
& T_{\mathrm{x}}=|T| \cos \left(\frac{\pi}{4}\right), \\
& T_{\mathrm{y}}=|T| \cos \left(\frac{\pi}{4}\right)
\end{aligned}
$$

where $T_{x}$ is the decomposition at $x$ axis by disease transmission vector $T$, and $T_{y}$ is the decomposition at $y$ axis by disease transmission vector $T$. In other words, the disease transmission vector $T$ has the equal chance to be transmitted in $x$ and $y$ direction.

2. The disease is centered in the major city (capital) of each county. Thus the $\Delta x$ and $\Delta y$ will be calculated based on the delta coordinates between the major cities. (The major city's coordinates was got from https://geohack.toolforge.org/ website)

3. The $\frac{\partial T_{\mathrm{x}}}{\partial x}$ can be approximately calculated as $\frac{\partial \mathrm{T}_{\mathrm{x}}}{\partial \mathrm{x}} \approx \frac{\mathrm{T}_{\mathrm{x}}-\mathrm{T}_{\mathrm{x} 1}}{|\mathrm{x} 1-\mathrm{x} 2|}$.

4. The $\frac{\partial T_{\mathrm{y}}}{\partial y}$ can be approximately calculated as $\frac{\partial T_{y}}{\partial y} \approx \frac{T_{y 2}-T_{y 1}}{|y 1-y 2|}$.

where $T_{x 1}$ is the $T_{x}$ value at location $1, T_{x 2}$ is the $T_{x}$ value at location 2. $T_{y l}$ is the $T_{y}$ value at location $1, T_{y 2}$ is the $T_{y}$ value at location 2 . 
Based on above assumption, the COVID19 infected quantities of each county is the scalar value of the transmission vector $\boldsymbol{T}$ in that county. The $T_{x}$ and $T_{y}$ are calculated by using equation (16) and (17). Then the $\frac{\partial T_{\mathrm{x}}}{\partial x}$ and $\frac{\partial T_{\mathrm{y}}}{\partial y}$ are calculated by using equation (18) and (19).

The cumulative COVID19 transmission data for the lower peninsula of the state of Michiagn by April 7, 2021 is obtained from Michigan Department of Helath website (Michigan Department of Health, 2021). The infected cases of each county at the lower peninsula of the state of Michigan are listed in the Table 1.

The div $\boldsymbol{T}$ is calculated by using equation (12) for the adjacent counties on the map, and curl $\boldsymbol{T}$ is calculated by using equation (15). The calculated data of the counties in the lower peninsula of Michigan are shown in Table 1.

Table 1. The calculated Divergence and Curl of the Counties in the Lower Peninsula of Michigan

\begin{tabular}{|c|c|c|c|c|c|c|c|c|c|c|c|}
\hline County & $\begin{array}{l}\text { Cases } \\
4 / 7 / 2021 \\
\end{array}$ & City & $y$ & $x$ & $\Delta x$ & $\Delta y$ & $T_{x}\left(T_{y}\right)$ & $\Delta T_{x}$ & $\Delta T_{y}$ & Div $T$ & Curl T \\
\hline Monroe & 10387 & Monroe & 41.92 & -83.40 & & -0.41 & 7347.64 & & 76371.76 & -187843.81 & $113446.77 \check{\mathrm{k}}$ \\
\hline Lenawee & 6935 & Adrian & 41.90 & -84.04 & 0.64 & -0.38 & 4905.74 & -2441.90 & 9306.40 & -28348.70 & $9166.23 \check{\mathrm{k}}$ \\
\hline Hillsdale & 3419 & Hillsdale & 41.92 & -84.63 & 0.60 & -0.32 & 2418.56 & -2487.18 & 5914.47 & -17594.62 & $16829.65 \check{\mathrm{k}}$ \\
\hline Branch & 3740 & Coldwater & 41.94 & -85.00 & 0.37 & -0.33 & 2645.63 & 227.07 & 4472.82 & -12280.02 & $10475.89 \breve{\mathrm{k}}$ \\
\hline St. Joseph & 4673 & Centreville & 41.92 & -85.53 & 0.53 & -0.37 & 3305.63 & 659.99 & 8037.35 & -22606.03 & $15815.23 \check{\mathrm{k}}$ \\
\hline CASS & 4196 & Cassopolis & 41.91 & -86.01 & 0.48 & -0.31 & 2968.20 & -337.42 & 860.89 & 8882.27 & $19986.54 \check{\mathrm{k}}$ \\
\hline Berrien & 12070 & Saint Joseph & 42.10 & -86.48 & 0.48 & & 8538.18 & 5569.98 & & & \\
\hline Wayne & 118350 & Detroit & 42.33 & -83.05 & & -0.31 & 83719.40 & & -82332.21 & 162660.26 & $-338051.77 \check{\mathrm{k}}$ \\
\hline Washtenaw & 20091 & Ann Arbor & 42.28 & -83.75 & 0.70 & -0.33 & 14212.14 & -69507.26 & -14109.57 & 34050.59 & $-39320.10 \breve{\mathrm{k}}$ \\
\hline Jackson & 11780 & Jackson & 42.24 & -84.41 & 0.66 & -0.34 & 8333.03 & -5879.10 & -8117.99 & 22035.56 & $-18311.43 \check{\mathrm{k}}$ \\
\hline Calhoun & 10063 & Marshall & 42.27 & -84.96 & 0.55 & -0.29 & 7118.45 & -1214.59 & -7008.10 & 30916.09 & $3369.29 \check{\mathrm{k}}$ \\
\hline Kalamazoo & 16035 & Kalamazoo & 42.29 & -85.59 & 0.63 & -0.36 & 11342.97 & 4224.52 & -11306.89 & 7072.71 & $-58289.61 \check{\mathrm{k}}$ \\
\hline Van Buren & 5413 & Paw Paw & 42.22 & -85.89 & 0.30 & -0.31 & 3829.09 & -7513.88 & -3761.89 & 12059.47 & \\
\hline Macomb & 72883 & $\begin{array}{l}\text { Mount } \\
\text { Clemens }\end{array}$ & 42.60 & -82.88 & & -0.38 & 1376.58 & & 6903.40 & -18021.58 & $16719.15 \check{\mathrm{k}}$ \\
\hline Oakland & 81263 & Pontiac & 42.65 & -83.29 & 0.41 & -0.41 & 1387.19 & -10.61 & 2881.19 & -5093.11 & $7665.29 \mathrm{k}$ \\
\hline Livingston & 11716 & Howell & 42.61 & -83.93 & 0.64 & -0.41 & 102.57 & 1284.62 & 18747.20 & -46038.16 & $36424.39 \check{\mathrm{k}}$ \\
\hline Ingham & 19044 & Mason & 42.58 & -84.44 & 0.51 & -0.40 & 215.05 & -112.47 & 2897.46 & -6935.96 & $7668.57 \check{\mathrm{k}}$ \\
\hline Eaton & 7263 & Charlotte & 42.56 & -84.83 & 0.39 & -0.44 & 110.35 & 104.69 & 3553.21 & -7907.55 & $7958.94 \breve{\mathrm{k}}$ \\
\hline Barry & 4041 & Hastings & 42.65 & -85.29 & 0.46 & -0.34 & 36.08 & 74.28 & 3310.58 & -9904.80 & $5772.59 \check{\mathrm{k}}$ \\
\hline Allegan & 7828 & Allegan & 42.53 & -85.86 & 0.56 & -0.43 & 67.20 & -31.13 & 39231.05 & -90824.38 & \\
\hline St. Clair & 11705 & Port Huron & 42.98 & -82.44 & & -0.44 & 8279.98 & & -6215.11 & 18689.66 & $2045.71 \check{\mathrm{k}}$ \\
\hline Lapeer & 6034 & Lapeer & 43.05 & -83.32 & 0.88 & -0.44 & 4268.38 & 4011.60 & -1557.67 & -35136.31 & $-37334.75 \check{\mathrm{k}}$ \\
\hline Genesee & 26647 & Flint & 43.02 & -83.69 & 0.38 & -0.40 & 18849.78 & -14581.39 & -7477.80 & 55775.44 & $21857.92 \check{\mathrm{k}}$ \\
\hline Shiawassee & 4400 & Corunna & 42.98 & -84.12 & 0.43 & -0.31 & 3112.51 & 15737.27 & -1235.81 & 2732.89 & $-4598.52 \check{\mathrm{k}}$ \\
\hline Clinton & 5179 & St. Johns & 43.00 & -84.56 & 0.44 & -0.29 & 3663.56 & -551.06 & -900.51 & 3708.84 & $-679.15 \check{\mathrm{k}}$ \\
\hline Ionia & 4731 & Ionia & 42.98 & -85.07 & 0.51 & -0.57 & 3346.65 & 316.91 & -1000.25 & -59292.48 & $-64863.81 \check{\mathrm{k}}$ \\
\hline Kent & 55554 & $\begin{array}{l}\text { Grand } \\
\text { Rapids }\end{array}$ & 42.96 & -85.66 & 0.59 & -0.27 & 39298.25 & -35951.59 & -31189.46 & 152540.01 & $25921.38 \check{\mathrm{k}}$ \\
\hline Ottawa & 24529 & Grand Haven & 43.06 & -86.23 & 0.57 & & 17351.53 & 21946.72 & -17351.53 & 0.00 & \\
\hline Sanilac & 2919 & Sandusky & 43.42 & -82.83 & & -0.38 & 2064.87 & & -319.74 & 1974.53 & $1124.79 \breve{\mathrm{k}}$ \\
\hline Tuscola & 3832 & Caro & 43.49 & -83.40 & 0.57 & -0.31 & 2710.71 & 645.85 & -965.58 & 18360.27 & $26088.64 \check{\mathrm{k}}$ \\
\hline Saginaw & 16076 & Saginaw & 43.42 & -83.96 & 0.57 & -0.07 & 11371.97 & 8661.26 & -8661.26 & 103240.04 & $-143044.22 \check{\mathrm{k}}$ \\
\hline Gratiot & 2653 & Ithaca & 43.29 & -84.60 & 0.64 & -0.30 & 1876.70 & -9495.27 & 4026.45 & -11396.74 & $11334.39 \check{\mathrm{k}}$ \\
\hline Montcalm & 3906 & Stanton & 43.29 & -85.08 & 0.48 & -0.32 & 2763.06 & 886.36 & 975.49 & -3622.44 & $121.76 \check{\mathrm{k}}$ \\
\hline Newaygo & 3317 & White Cloud & 43.55 & -85.77 & 0.69 & -0.05 & 2346.41 & -416.65 & 607.65 & -910.80 & 124755.81 k \\
\hline Muskegon & 11463 & Muskegon & 43.23 & -86.25 & 0.48 & -0.46 & 8108.79 & 5762.38 & -6459.87 & 13900.50 & \\
\hline Huron & 2467 & Bad Axe & 43.80 & -83.00 & & -0.18 & 1745.13 & & -1205.39 & 13179.38 & $2904.45 \check{\mathrm{k}}$ \\
\hline Tuscola & 3832 & Caro & 43.49 & -83.40 & 0.40 & -0.49 & 2710.71 & 965.58 & -1665.19 & -2651.17 & $13065.00 \check{\mathrm{k}}$ \\
\hline Bay & 8345 & Bay City & 43.60 & -83.89 & 0.49 & -0.43 & 5903.16 & 3192.44 & -4801.04 & 9759.29 & $-14307.76 \check{\mathrm{k}}$ \\
\hline Midland & 5285 & Midland & 43.62 & -84.25 & 0.36 & -0.26 & 3738.55 & -2164.61 & -2845.12 & 9137.29 & $-7010.68 \breve{\mathrm{k}}$ \\
\hline Isabella & 4176 & $\begin{array}{l}\text { Mount } \\
\text { Pleasant }\end{array}$ & 43.60 & -84.77 & 0.52 & -0.30 & 2954.05 & -784.49 & -2643.51 & 11221.72 & $-13430.62 \check{\mathrm{k}}$ \\
\hline Mecosta & 2331 & Big Rapids & 43.70 & -85.48 & 0.71 & -0.26 & 1648.92 & -1305.13 & -648.68 & 973.35 & $1609.58 \mathrm{k}$ \\
\hline Newaygo & 3317 & White Cloud & 43.55 & -85.77 & 0.29 & 43.55 & 2346.41 & 697.48 & -2346.41 & -53.88 & \\
\hline Oceana & 2025 & Hart & 43.70 & -86.37 & 0.59 & -0.57 & 1432.46 & -913.95 & -457.68 & 802.17 & \\
\hline
\end{tabular}




\begin{tabular}{|c|c|c|c|c|c|c|c|c|c|c|c|}
\hline Arenac & 763 & Standish & 43.98 & -83.96 & & -0.29 & 539.74 & & 435.04 & -563.32 & $2582.20 \breve{\mathrm{k}}$ \\
\hline Gladwin & 1478 & Gladwin & 43.98 & -84.49 & 0.53 & -0.29 & 1045.52 & 505.78 & -292.15 & 1180.87 & $-746.42 \check{\mathrm{k}}$ \\
\hline Clare & 1558 & Harrison & 44.02 & -84.80 & 0.31 & -0.48 & 1102.11 & 56.59 & -148.55 & 17.14 & $-646.67 \check{\mathrm{k}}$ \\
\hline Osceola & 1263 & Reed City & 43.88 & -85.51 & 0.71 & -0.46 & 893.43 & -208.68 & -190.99 & -1281.63 & $-1830.82 \breve{\mathrm{k}}$ \\
\hline Lake & 439 & Baldwin & 43.90 & -85.85 & 0.34 & -0.35 & 310.54 & -582.89 & 1102.82 & -1959.85 & $3819.86 \check{\mathrm{k}}$ \\
\hline Mason & 1414 & Ludington & 43.96 & -86.44 & 0.59 & -0.29 & 1000.25 & 689.70 & -383.40 & 1337.46 & \\
\hline Iosco & 1378 & Tawas City & 44.27 & -83.52 & & -0.39 & 974.78 & & -661.41 & 1395.73 & $-1496.74 \breve{\mathrm{k}}$ \\
\hline Ogemaw & 1065 & West Branch & 44.28 & -84.24 & 0.71 & -0.38 & 753.37 & -221.41 & -468.29 & 1804.54 & $-781.49 \breve{\mathrm{k}}$ \\
\hline Roscommon & 1348 & Roscommon & 44.50 & -84.59 & 0.36 & -0.16 & 953.56 & 200.19 & -421.60 & 2155.16 & $-2203.30 \breve{\mathrm{k}}$ \\
\hline Missaukee & 993 & Lake City & 44.33 & -85.21 & 0.62 & -0.40 & 702.44 & -251.12 & -149.97 & 4175.98 & 966.52 k \\
\hline Wexford & 1998 & Cadillac & 44.25 & -85.40 & 0.19 & -0.52 & 1413.36 & 710.93 & 1875.29 & -4484.33 & $497.77 \check{\mathrm{k}}$ \\
\hline Manistee & 872 & Manistee & 44.24 & -86.32 & 0.92 & -0.39 & 616.84 & -796.52 & 0.00 & 0.00 & \\
\hline Alcona & 443 & Harrisville & 44.66 & -83.29 & & -0.40 & 313.37 & & 680.51 & -1718.77 & $744.92 \check{\mathrm{k}}$ \\
\hline Oscado & 403 & Mio & 44.65 & -84.13 & 0.84 & -0.35 & 285.08 & -28.30 & -33.25 & 519.16 & $643.15 \check{\mathrm{k}}$ \\
\hline Crawford & 752 & Grayling & 44.66 & -84.71 & 0.58 & -0.36 & 531.96 & 246.88 & 527.71 & -1415.39 & $1181.51 \breve{\mathrm{k}}$ \\
\hline Kalkaska & 781 & Kalkaska & 44.73 & -85.18 & 0.47 & -0.24 & 552.47 & 20.51 & 186.75 & 5406.50 & $11862.75 \check{\mathrm{k}}$ \\
\hline Grand & 4649 & Traverse City & 44.77 & -85.62 & 0.44 & -0.23 & 3288.65 & 2736.18 & -2656.95 & 6167.32 & $-17484.68 \check{\mathrm{k}}$ \\
\hline \multicolumn{12}{|l|}{ Traverse } \\
\hline Benie & 872 & Beulah & 44.63 & -86.10 & 0.47 & & 616.84 & -2671.81 & -616.84 & 0.00 & \\
\hline Alpena & 1405 & Alpena & 45.06 & -83.43 & & -0.36 & 993.88 & & -506.49 & 374.35 & $-2789.53 \check{\mathrm{k}}$ \\
\hline Montmorency & 356 & Atlanta & 45.00 & -84.14 & 0.71 & -0.64 & 251.83 & -742.05 & 561.67 & 641.71 & $2312.10 \breve{\mathrm{k}}$ \\
\hline Otsego & 1498 & Gaylord & 45.02 & -84.68 & 0.53 & -0.35 & 1059.67 & 807.84 & 21.93 & -668.47 & $-877.77 \check{\mathrm{k}}$ \\
\hline Antrim & 1045 & Bellaire & 44.97 & -85.21 & 0.53 & & 739.22 & -320.45 & -16.27 & -249.73 & \\
\hline \multirow[t]{2}{*}{ Leelanau } & 893 & Suttons Bay & 44.99 & -85.64 & 0.43 & & 631.70 & -107.52 & -631.70 & 0.00 & \\
\hline & & Township & & & & & & & & & \\
\hline Presque Isle & 689 & Rogers City & 45.42 & -83.82 & & & 487.39 & & & & \\
\hline Cheboygan & 1150 & Cheboygan & 45.65 & -84.47 & 0.66 & & 813.50 & 326.11 & & & \\
\hline Emmet & 1529 & Petoskey & 45.37 & -84.96 & 0.48 & & 1081.60 & 268.10 & & & \\
\hline Charlevoix & 1022 & & & & & & 722.95081 & -358.646 & & & \\
\hline
\end{tabular}

\section{Discussion}

The COVID19 is a pandemic that is transmitted rapidly all over world. In the state of Michigan, the daily confirmed cases have been gone through several waves, and continue to increase. The transmission dynamics have been explored in this paper which the divergence and curl have been calculated for transmission vector $T$.

The divergence is positive which means the COVID 19 transmitted outward of the county. The divergence is negative which means the COVID 19 transmitted inward of the county. The results shows Wayne county had the highest divergence (162660), the Kent county had the second highest divergence (152540), and the Saginaw county had the third highest divergence (103240) and so on so forth. This means the COVID 19 transmitted outward to other places. The Monroe county had the divergence number -187843 which is the lowest number in divergence. The Allegan county had the divergence number -90824 which is the second lowest number in divergence. This means the COVID19 transmitted inward from other places.

The divergences of Row 1 to Row 10 (see Figure 4) counties were plotted in Figure 5 to Figure 14. The divergences of Row 1 counties are almost all negative which means the COVID19 was transmitted into Row 1 counties. The divergences of Row 2 counties are all positive which means the COVID19 was transmitted from Row 2 counties. The divergences of Row 3 counties are all negative which means the COVID19 was transmitted into Row 3 counties, etc.

The direction of vector curls is in $z$ direction, the positive of curls means the transmission vector rotates to counter-clockwise direction, the negative of curls means transmission vector rotates to clockwise direction. The curl at Wayne county is $-338051 \check{\mathrm{k}}$, which is the largest absolute magnitude value in curl. This means the COVID 19 transmitted vector $T$ rotates in clockwise. The curl at Newaygo county is $124755 \mathrm{k}$ which has the largest positive magnitude value. This means the COVID 19 transmitted vector T rotates in the counter-clockwise.

The imaginary part of the curls of Row 1 to Row 10 counties was plotted in Figure 15 to Figure 24. The curl of Row 1 counties are all positive which means the COVID19 has circulated in the counter-clockwise direction at Row 1 counties. The curl of row 2 counties are all negative which means the COVID19 has circulated in the clockwise at Row 2 counties. The curl of row 3 counties are all positive which means the COVID19 has circulated in the counter-clockwise direction at Row 3 counties, etc. 


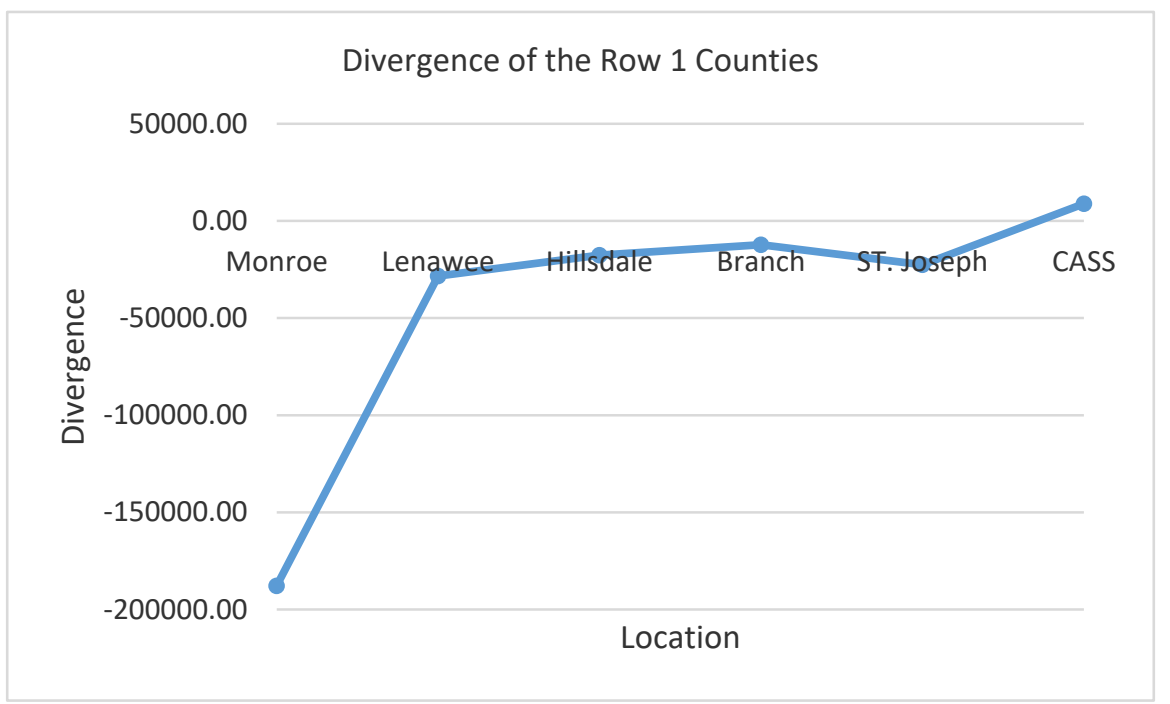

Figure 5. Divergence of Row1 counties

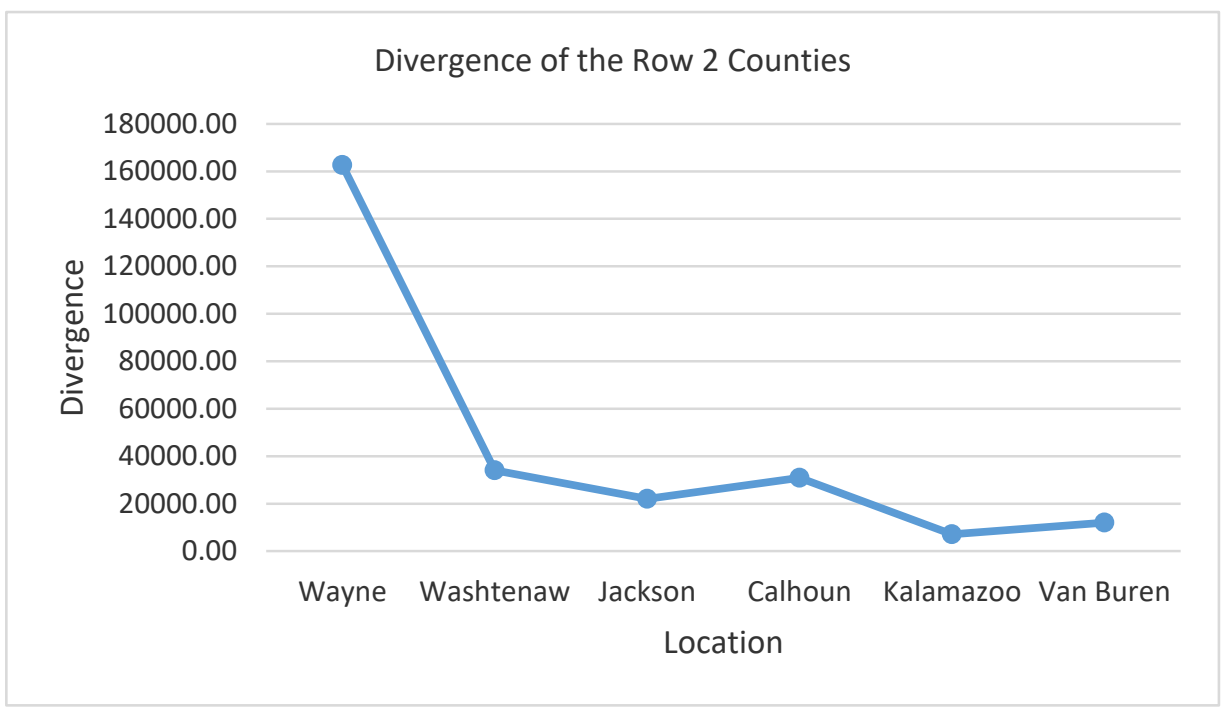

Figure 6. Divergence of Row2 counties

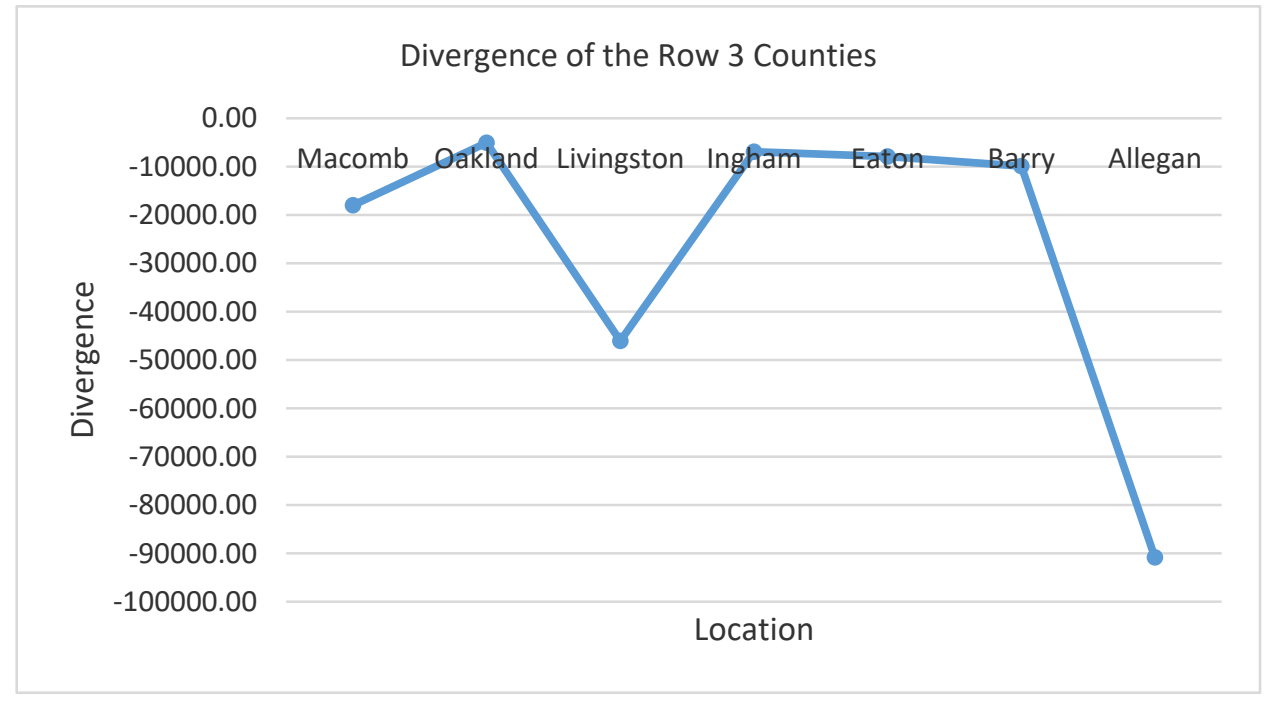

Figure 7. Divergence of Row3 counties 


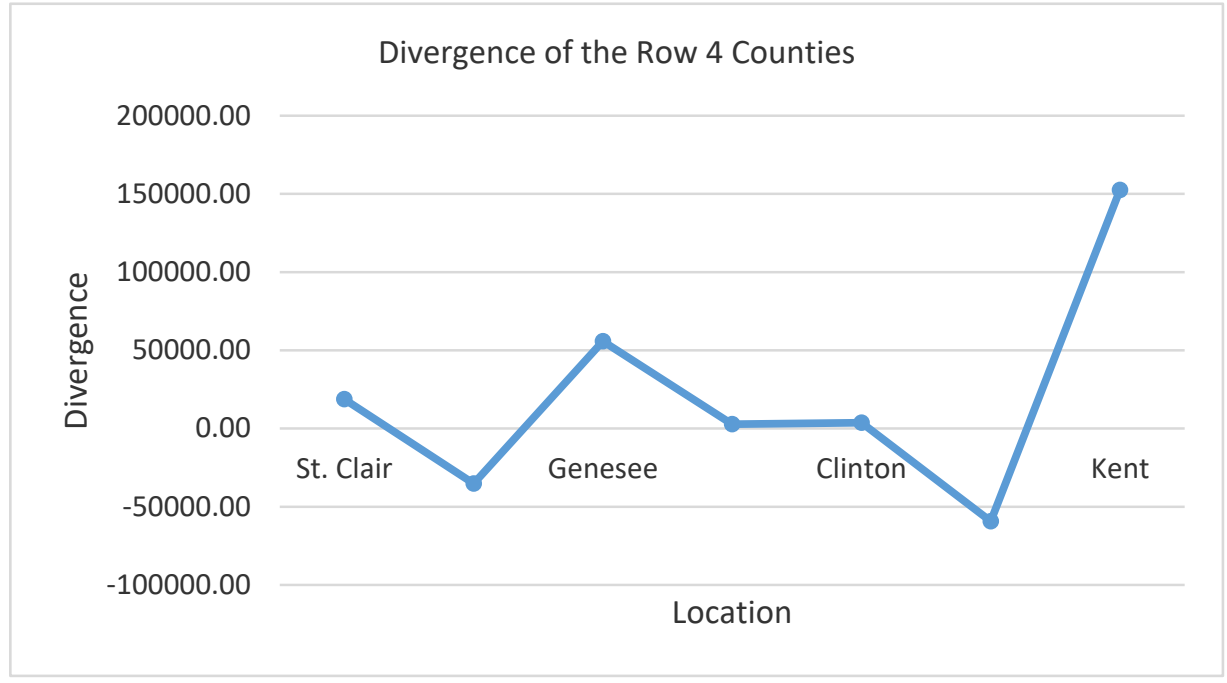

Figure 8. Divergence of Row4 counties

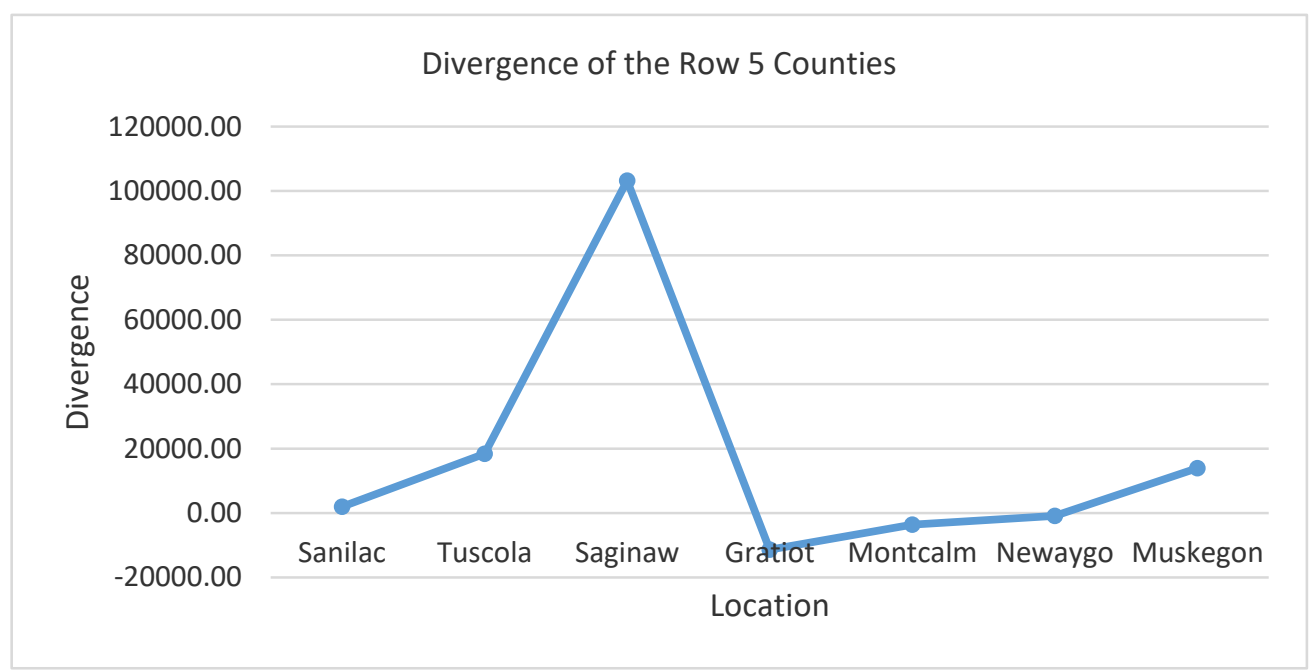

Figure 9. Divergence of Row5 counties

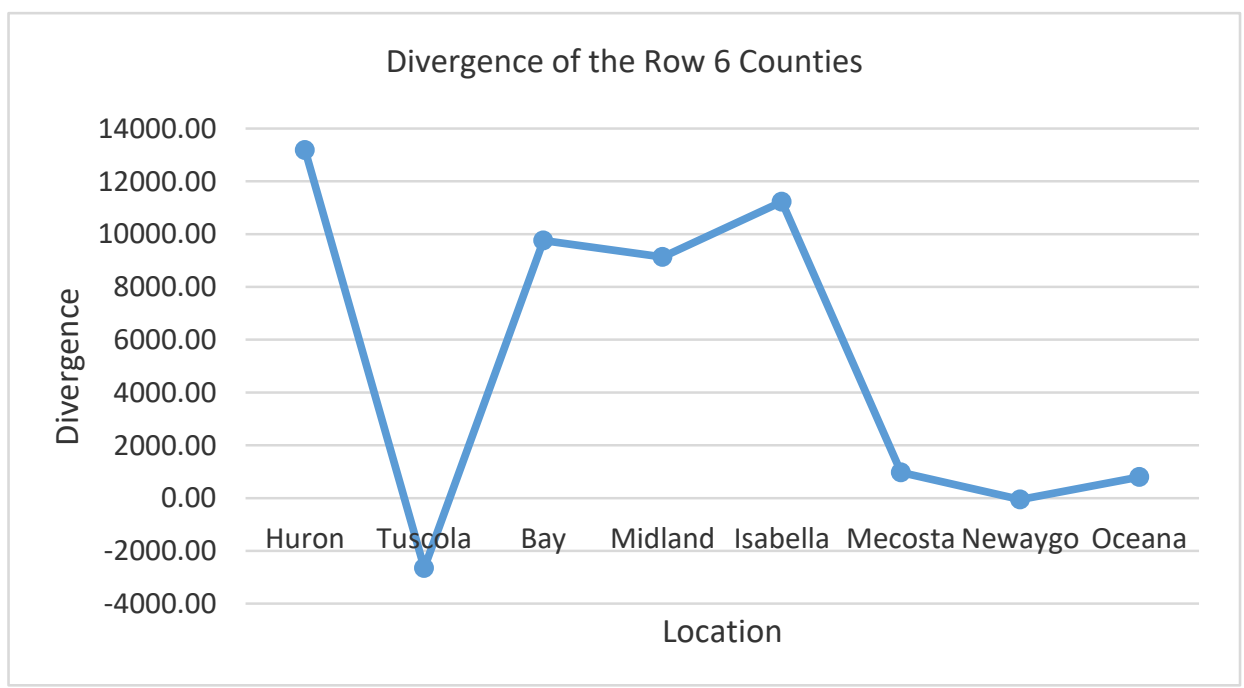

Figure 10. Divergence of Row6 counties 


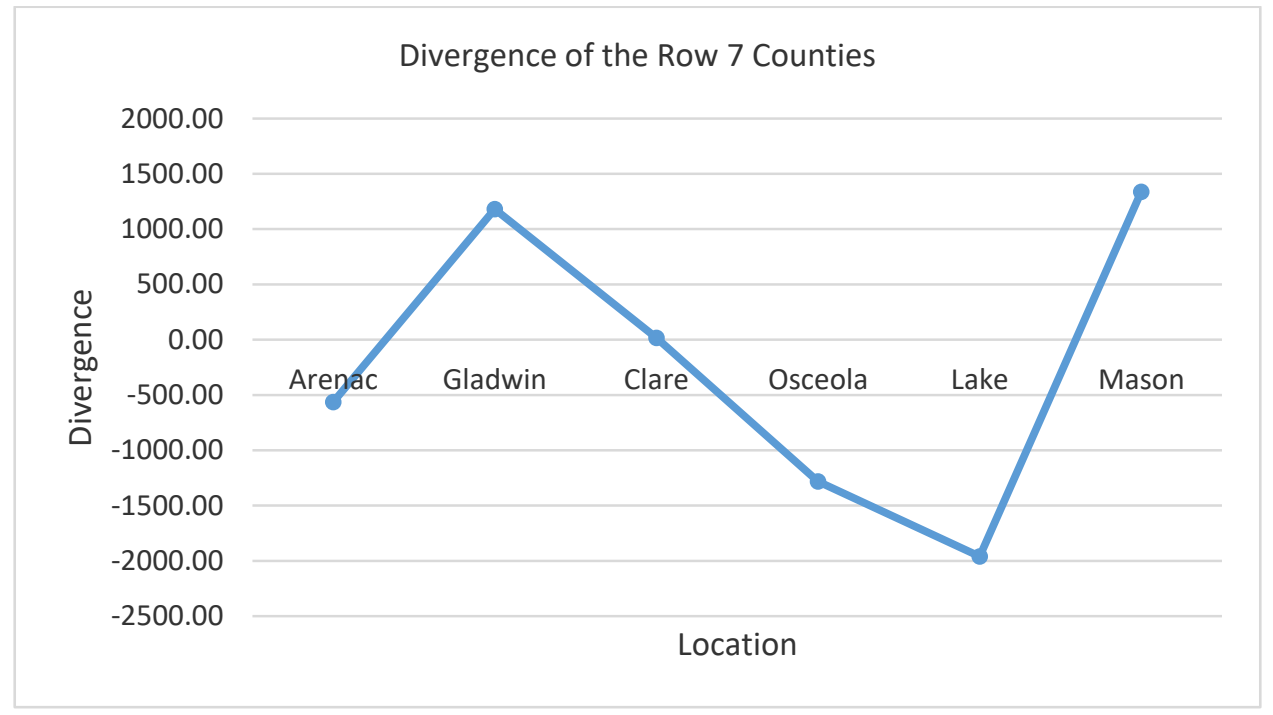

Figure 11. Divergence of Row7 counties

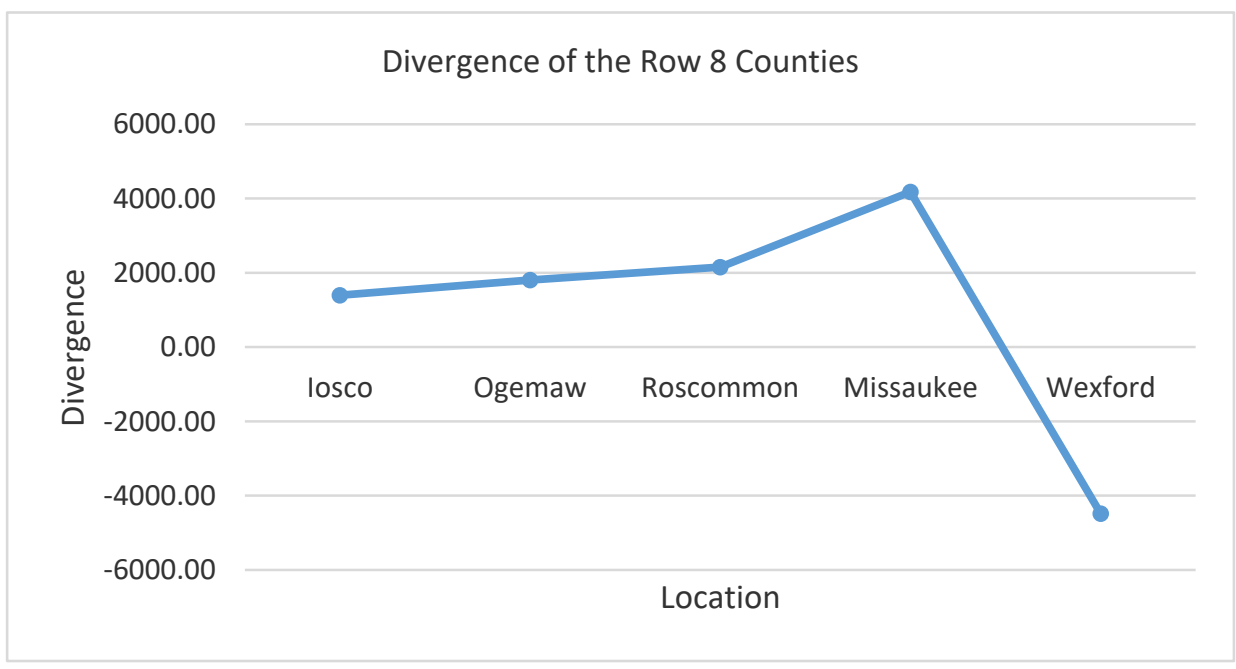

Figure 12. Divergence of Row8 counties

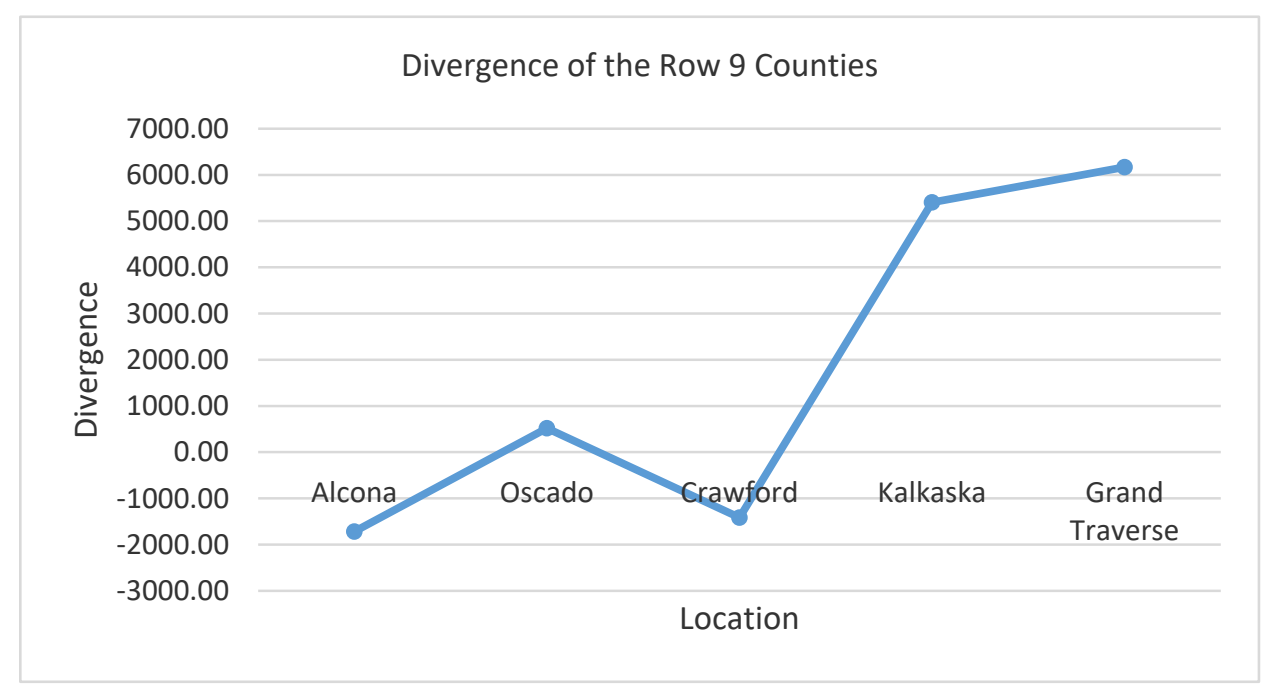

Figure 13. Divergence of Row9 counties 


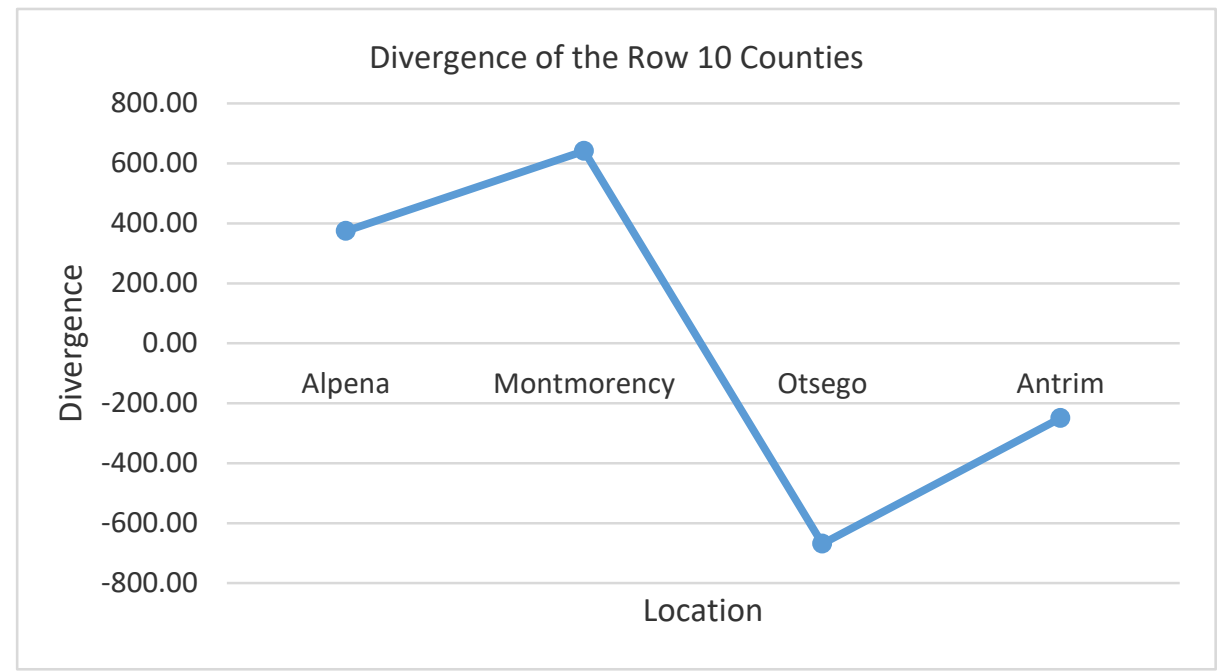

Figure 14. Divergence of Row10 counties

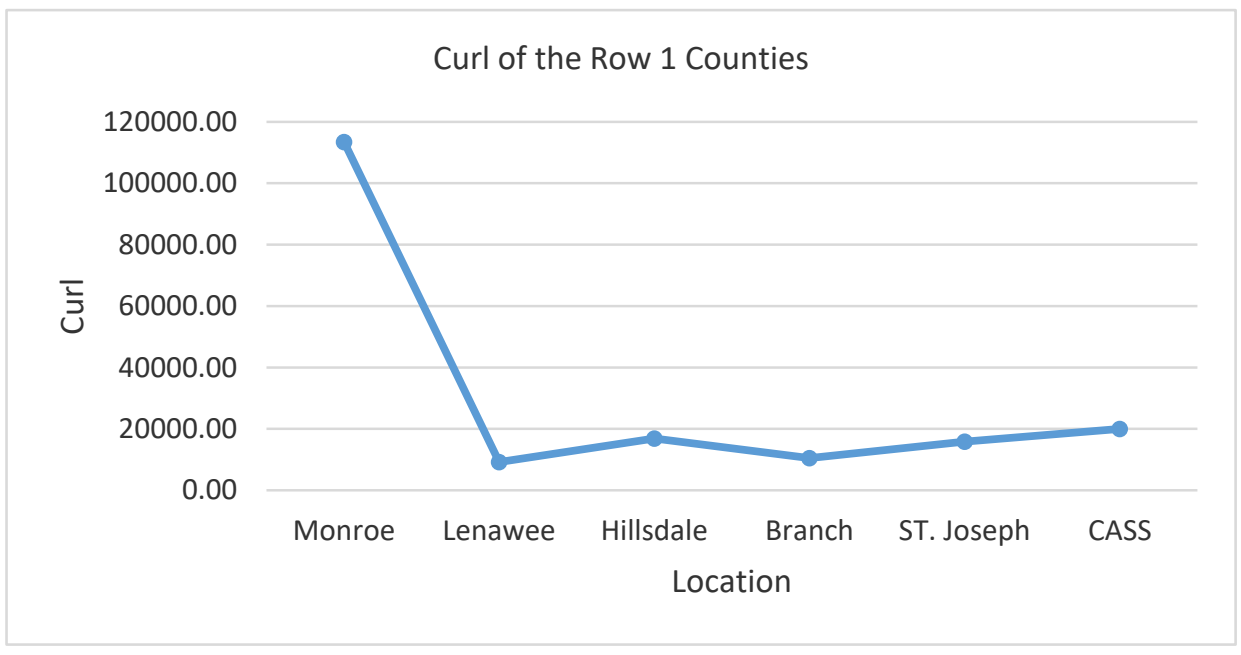

Figure 15. The imaginary part of curls at Row 1 counties

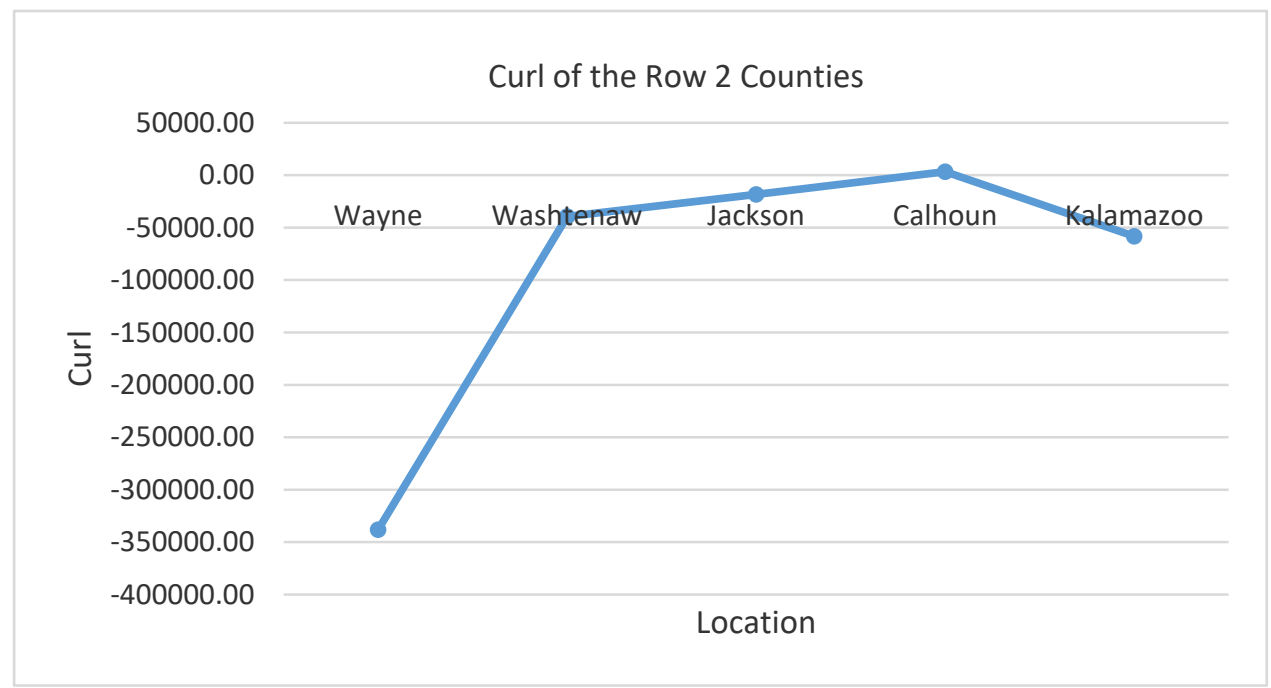

Figure 16. The imaginary part of curls at Row 2 counties 


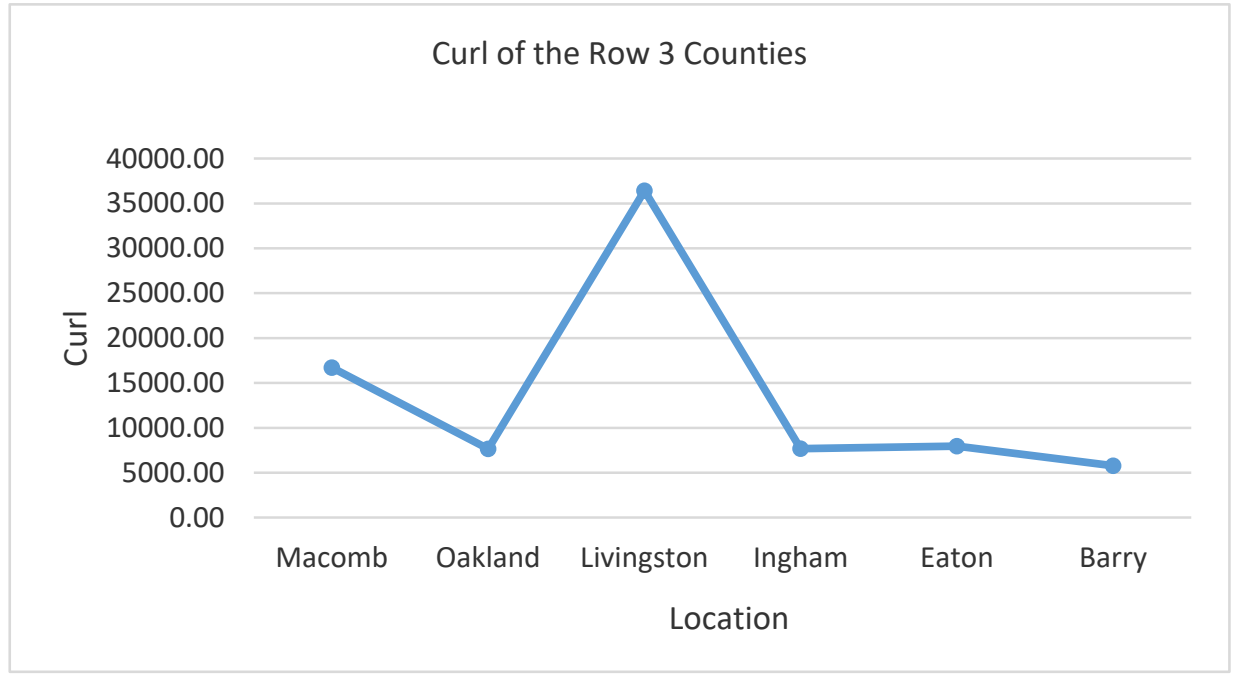

Figure 17. The imaginary part of curls at Row 3 counties

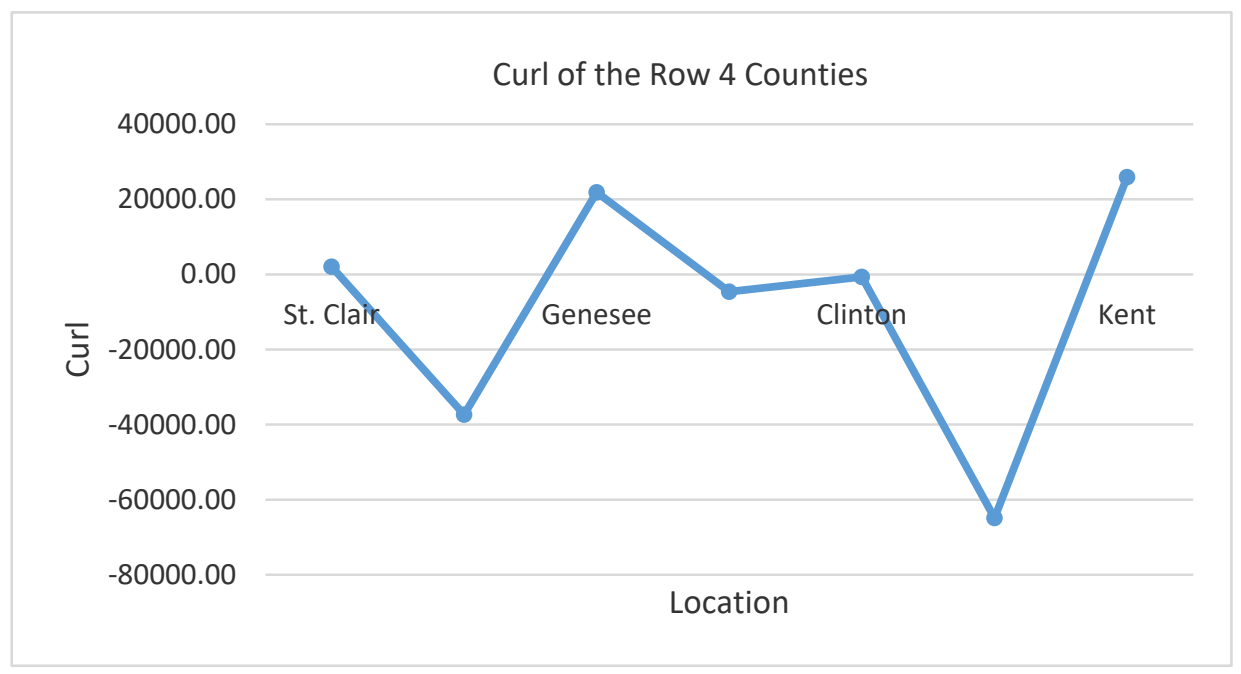

Figure 18 . The imaginary part of curls at Row 4 counties

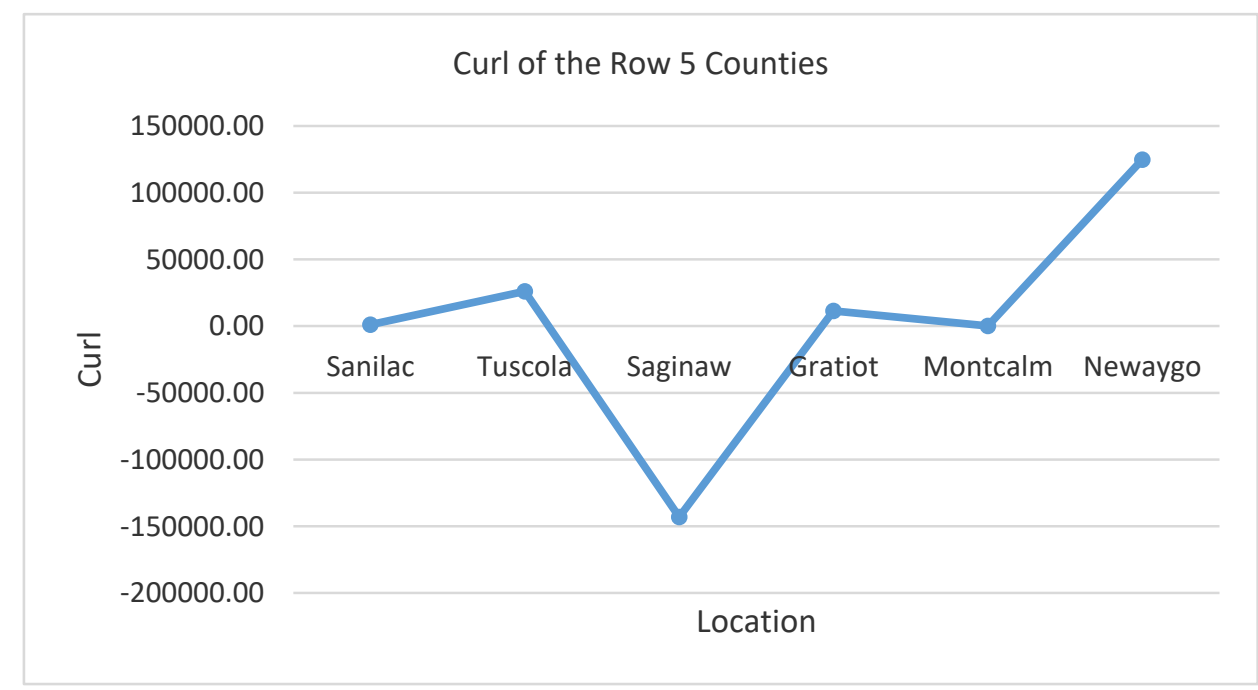

Figure 19. The imaginary part of curls at Row 5 counties 


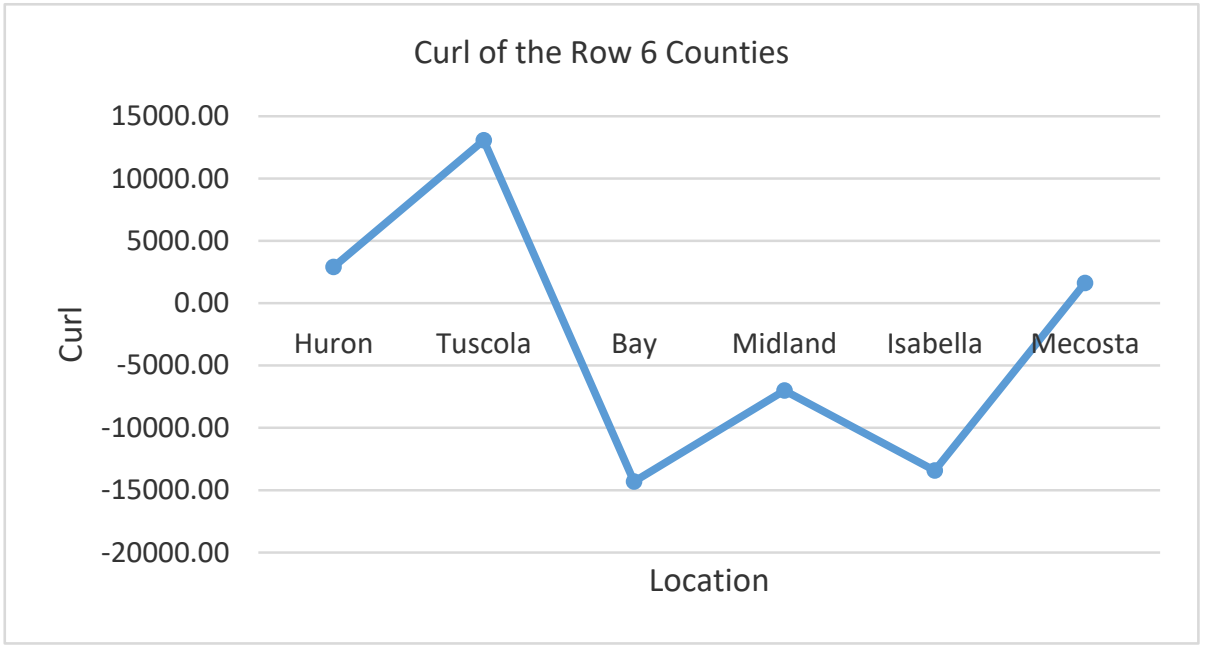

Figure 20. The imaginary part of curls at Row 6 counties

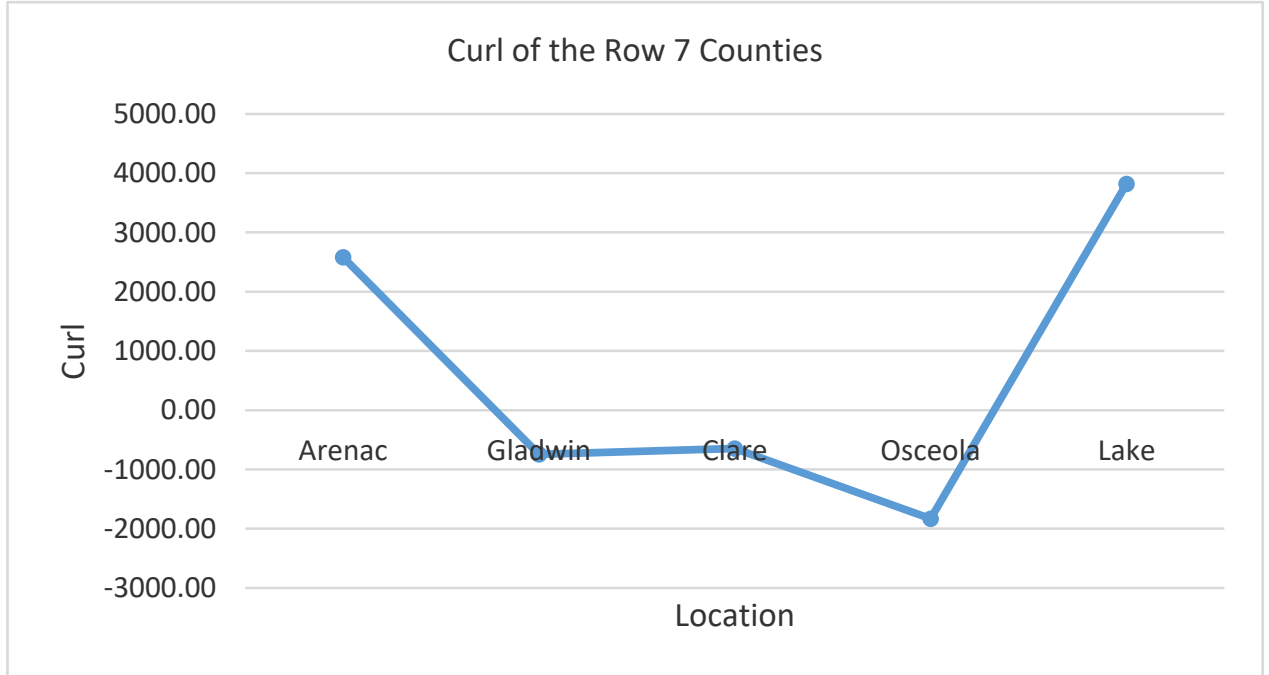

Figure 21. The imaginary part of curls at Row 7 counties

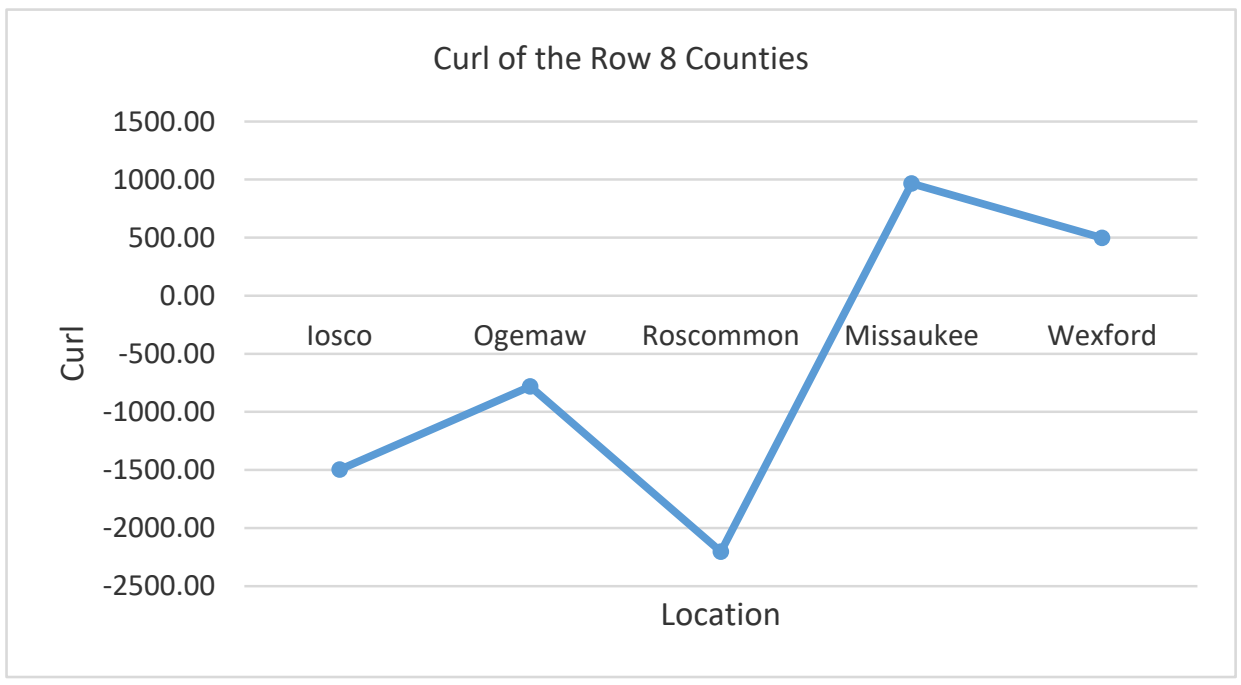

Figure 22. The imaginary part of curls at Row 8 counties 


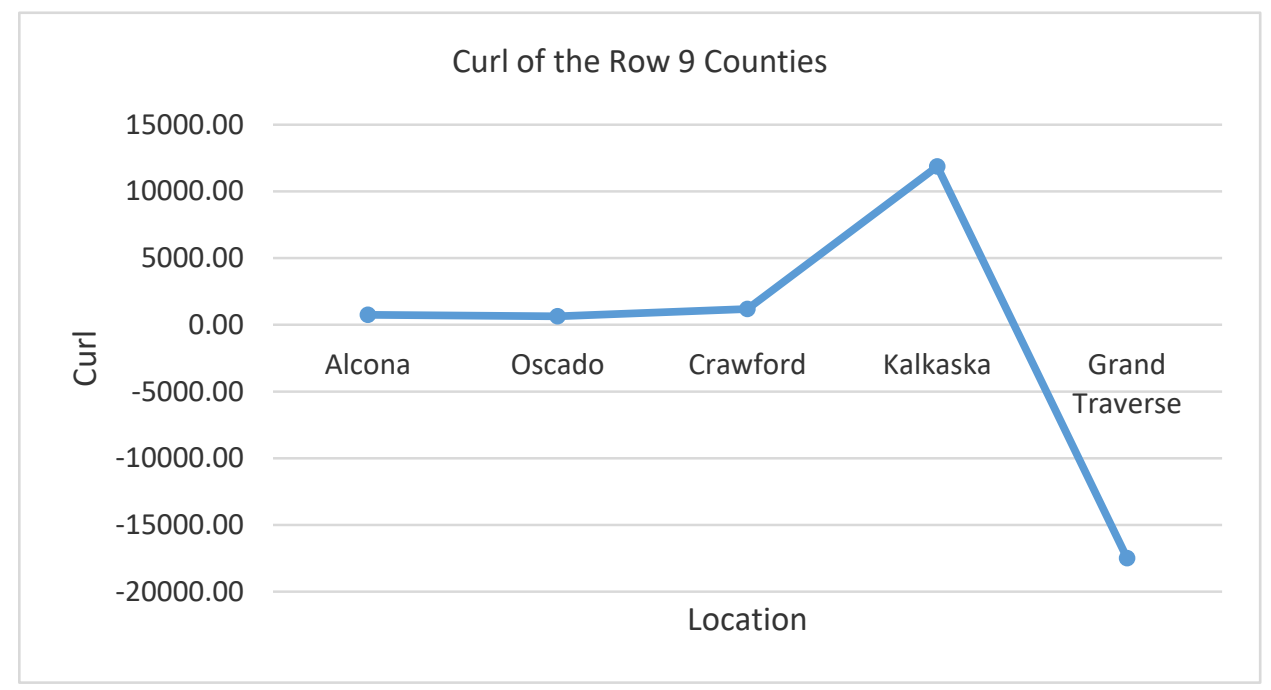

Figure 23. The imaginary part of curls at Row 9 counties

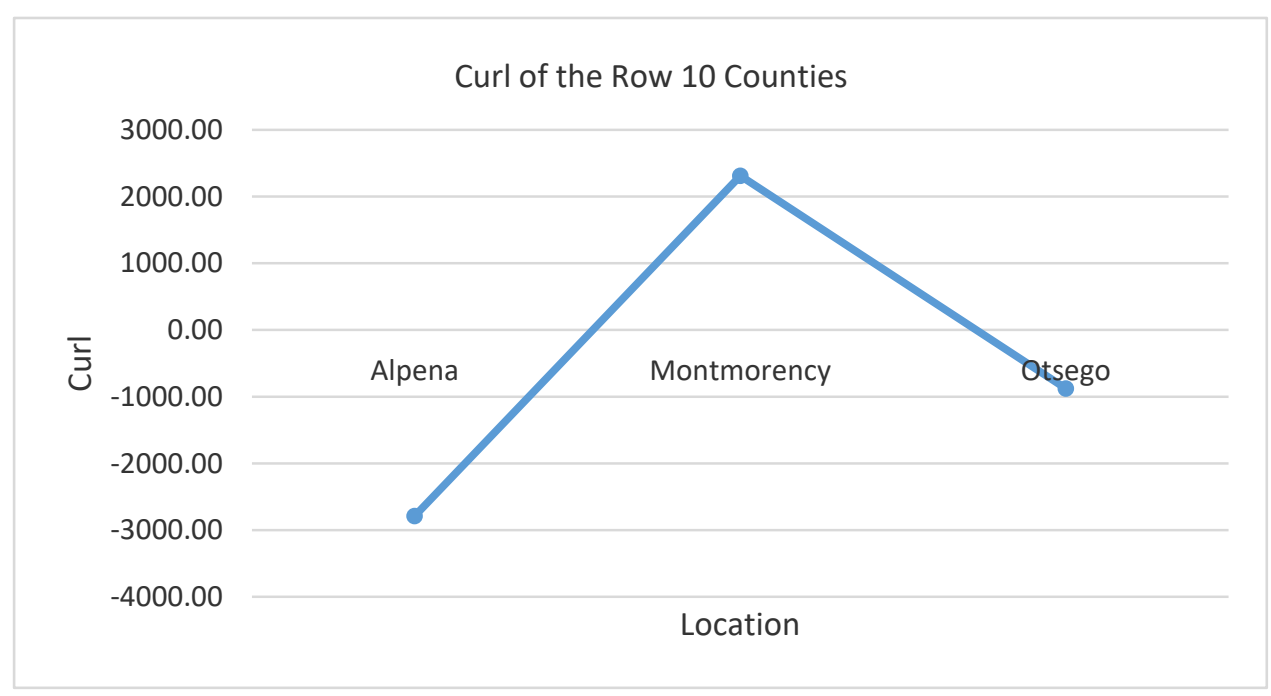

Figure 24. The imaginary part of curls at Row 10 counties

\section{Conclusion}

This paper is using the vector divergence and curl operator to describe the transmission density and circulation density of COVID19 at the lower peninsula of the state of Michigan. This method can be used to describe the transmission pattern and dynamics for pandemic COVID19 from one location to another location. The public health policy makers can refer to the COVID19 divergence and curl data when making the executive orders to slow down the transmission. The concept using COVID19 transmission $T$ as a vector field may help the researchers to understand better for the dynamic transmissions.

In future research, the divergence and curl can be applied to a smaller contained space. In this way, the transmission pattern and dynamics of COVID19 can be calculated more accurately. The more accurate of the transmission data is collected, the more accurate of the divergence and curl will be calculated.

\section{Acknowledgments}

The author give thanks to WorldOmeters and the Michigan Department of Health for providing the COVID19 data in their website, also thanks to geohack website which provides the major city's coordinates, also thanks to the mapofworld website to provide the map of Michigan.

\section{References}

Bhardwaj, R. (2020). A Predictive Model for the Evolution of COVID-19 [published online ahead of print, 2020 
Jun 22]. Transactions of the Indian National Academy of Engineering. 2020; 1-8.

Canabarro A., Tenório E., Martins R., Martins L., Brito S., \& Chaves R. (2020). Data-driven study of the COVID-19 pandemic via age-structured modelling and prediction of the health system failure in Brazil amid diverse intervention strategies. PLOS ONE, 15(7), e0236310.

https://doi.org/10.1371/journal.pone.0236310

Geohack. (2021). Retrieved from https://geohack.toolforge.org/

Liu, Z., Magal, P., \& Webb, G. (2021). Predicting the number of reported and unreported cases for the COVID-19 epidemics in China, South Korea, Italy, France, Germany and United Kingdom. Journal of Theoretical Biology, 509, 110501. https://doi.org/10.1016/j.jtbi.2020.110501

Ma, J. (2020). Estimating epidemic exponential growth rate and basic reproduction number. Infectious Disease Modelling, 5, 129-141. https://doi.org/10.1016/j.idm.2019.12.009

Map of world. (2020). The Map of Lower Peninsula of Michigan with Major cities and county capitals. Retrieved from https://www.mapsofworld.com/usa/states/michigan/michigan-county-map.html

Michigan Department of Health (2021). Retrieved from https://www.michigan.gov/coronavirus/0,9753,7-406-98163_98173---,00.html

Ranjan, R. (2020). Predictions for COVID-19 Outbreak in India Using Epidemiological Models. medRxiv preprint. https://doi.org/10.1101/2020.04.02.20051466

Riley, K. F., Hobson, M. P., \& Bence, S. J. (2010). Mathematical methods for physics and engineering. Cambridge University Press, 2010, ISBN 978-0-521-86153-3.

Spiegel, M. R., Lipschutz, S., \& Spellman, D. (2009). Vector Analysis (2nd Edition). Schaum's Outlines, McGraw Hill (USA), 2009, ISBN 978-0-07-161545-7.

Wang, Y. (2020). Predict new cases of the coronavirus 19; in Michigan, U.S.A. or other countries using Crow-AMSAA method. Infectious Disease Modelling, 5, 459-477. https://doi.org/10.1016/j.idm.2020.07.001

WorldOMeters. (2021). Retrieved from https://www.worldometers.info/coronavirus/country/us/

Wu, W. Y. (1989). Fluid Dynamics. Peking University Press. Beijing, China, August, 1989. ISBN7-301-00198-3/0.029.

\section{Copyrights}

Copyright for this article is retained by the author(s), with first publication rights granted to the journal.

This is an open-access article distributed under the terms and conditions of the Creative Commons Attribution license (http://creativecommons.org/licenses/by/4.0/). 